\title{
The Effect of Foot Reflexology on Hospital Anxiety and Depression in Female Older Adults: a Randomized Controlled Trial
}

Tahereh Bahrami, MScN, ${ }^{1}$ Nahid Rejeh, PhD, MScN, BScN,${ }^{2 *}$ Majideh Heravi-Karimooi, PhD, $\mathrm{MScN}, \mathrm{BScN},{ }^{2}$ Seyed Davood Tadrisi, $\mathrm{MScN},{ }^{3}$ Mojtaba Vaismoradi, PhD, MScN, BScN ${ }^{4}$

${ }^{1}$ Department of Nursing, Faculty of Nursing and Midwifery, Shahed University, Tehran, Iran, ${ }^{2}$ Elderly Care Research Center, Department of Nursing, Faculty of Nursing and Midwifery, Shahed University, Tehran, Iran, ${ }^{3}$ Faculty of Nursing, Baqiyatallah University of Medical Sciences, Tehran, Iran, ${ }^{4}$ Faculty of Nursing and Health Sciences, Nord University, Bodø, Norway

Background: Patients with cardiovascular diseases usually suffer from hospital anxiety and depression.

Aim: This study aimed to investigate the effect of foot reflexology massage on anxiety and depression in female older adults suffering from acute coronary syndrome.

Participants: Ninety older women with acute coronary syndrome were randomly assigned into intervention and control groups $(n=45$ in each group).

Research Design: A randomized controlled trial.

Intervention: The intervention and control groups received foot reflexology massage and routine care, respectively.

Main Outcomes Measures: The levels of anxiety and depression were evaluated using the hospital's anxiety and depression scale (HADS) before and immediately after foot reflexology massage.

Results: Foot reflexology massage reduced both anxiety $(\mathrm{F}(1.44)=19.11, p=.001)$ and depression $(F(1.44)=16.76, p=.001)$ in acute coronary patients relative to control patients. The intervention had a large effect on hospital anxiety and depression.

Conclusions: Foot reflexology massage is an efficient and safe intervention for alleviating psychological responses among female older adults suffering from acute coronary syndrome during hospitalization.

KEY WORDS: acute coronary syndrome; anxiety; depression; hospital; reflexology

\section{INTRODUCTION}

Anxiety and depression are common psychological responses in patients with cardiovascular diseases during hospitalization. ${ }^{(1)}$ It has been reported that $20 \%$ of these patients have the symptoms of anxiety and depression. ${ }^{(2,3)}$ Older people with acute coronary syndrome (ACS) often experience emotional problems that can influence their health status. ${ }^{(4-6)}$ Anxiety and depression in older people reduce their daily performance and well-being. ${ }^{(7)}$ During hospitalization they may experience a higher rate of functional deterioration and reduced quality of life compared to younger patients. ${ }^{(8)}$

Massage therapy has been used as one part of complementary therapies for patients with different health conditions. ${ }^{(9)}$ Foot reflexology, as one type of massage therapy, stimulates specific reflex/reflexology areas on feet and can improve homeostasis. ${ }^{(10-13)}$ Reflex areas are the representative of different body organs that can be stimulated through neural pathways or hormone-like activities. ${ }^{(14)}$ The pressure applied in the reflexology massage intervention breaks down calcium crystals and uric acid in nerve pathways and causes psychological responses. ${ }^{(15,16)}$

The effects of reflexology massage as a safe and non-invasive nursing intervention have been studied in different clinical situations. Therefore, the effects of reflexology massage on relieving anxiety and other physiological parameters, ${ }^{(17)}$ pain and fatigue, ${ }^{(18)}$ and stress ${ }^{(19)}$ have been shown. Soheili et al. ${ }^{(20)}$ found a significant reduction in the severity of anxiety, stress, and depression after the use of reflexology massage. However, Gunnarsdottir and Jonsdottir's study ${ }^{(21)}$ did not support the effectiveness of reflexology massage for reducing anxiety.

The use of complementary and alternative therapies by older patients with heart diseases is increasing.(22) However, to the best of our knowledge, no study has been conducted to investigate the effect of foot reflexology massage on anxiety and depression among older adults in hospital settings. Therefore, the present study aimed to investigate the effect of foot reflexology massage on anxiety and depression in female older adults suffering from acute coronary syndrome.

\section{METHODS}

\section{Hypothesis}

Statistically significant differences are reported between intervention and control groups in terms 
of hospital anxiety and depression after foot reflexology massage.

\section{Design}

This was a randomized controlled trial with a preand post-intervention design.

\section{Participants}

The study participants were 90 older people aged 60 years and over who were hospitalized for one day in the cardiac care unit (CCU), and were diagnosed with ACS. They were recruited using a convenience sampling method from a high-turnover CCU of a teaching hospital in Tehran, Iran. They were randomly assigned into either the intervention group or the control group ( $\mathrm{n}=45$ in each group), with no patient declining to participate. Sampling was started sequentially from July 2014 to December 2015 and was continued until the required numbers of samples were recruited.

Eligibility criteria for the recruitment were: diagnosed with ACS consisting of angina pectoris and myocardia infraction by the cardiologist, aged 60 years old and older (the beginning of old age in developing countries), ability to understand and communicate in Farsi, no anxiolytics and sedative medications in the last four hours before the intervention, no alternative and complementary therapies during the last 48 hours before the intervention, and no foot ulcers and history of drug addiction.

Only female older people with ACS were recruited to eliminate the influence of gender on anxiety or depression. Exclusion criteria were the presence of hemodynamic instabilities during the intervention and unwillingness to collaborate with the intervention (Figure 1).

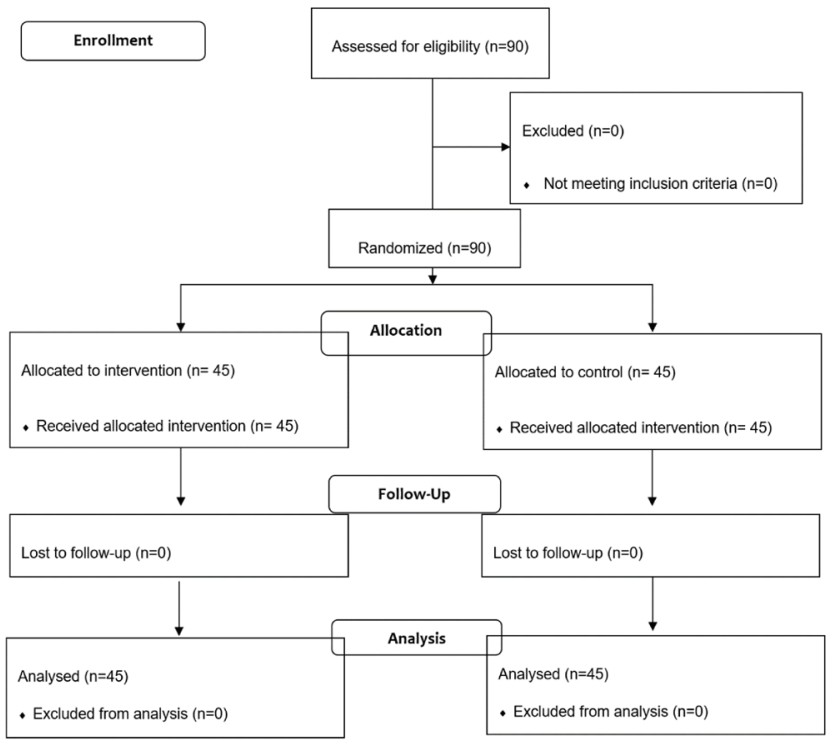

FIGURE 1. The process of the study according to the Consort flow diagram (2010)

\section{Sample Size}

The sample size was estimated using a statistical power analysis with the consideration of $\alpha=0.05, \beta$ $=15 \%$, power $=90 \%$, Altman's Nomogram, and also the sample size of a previous study. ${ }^{(23)}$

\section{Measurement Tools}

Data was collected using the following instruments:

- Personal and medical data form: It contained questions regarding demographic characteristics of the older people including age, the marital status, education level, employment status, living status, and history of hospitalization.

- Abbreviated mental test (AMT): It helped with the assessment of older people in terms of the presence of cognitive disorders and a score greater than 7 was considered the normal status. A score lower than 7 out of 10 indicated cognitive impairments. ${ }^{(24)}$ For reliability, the Cronbach's alpha coefficient of the AMT was $0.76 .^{(25)}$

- Hospital depression and anxiety scale (HADS): It evaluated hospital anxiety and depression levels and was consisted of 14 items, including 7 items for each subscale of anxiety (HADS-A) and depression (HADS-D). As a self-rating scale, its scoring system ranged from the absence of symptoms (score 0 ) to the maximal presentation of symptoms (score 3); a higher score indicated a higher level of anxiety or depression. (26) Correlations between the two subscales varied from 0.40 to 0.74 , with a mean score of 0.56 . The Cronbach's alpha coefficient of the HADS-A varied from 0.68 to 0.93 with a mean score of 0.83 , but the Cronbach's alpha coefficient of the HADS-D was 0.67 to 0.90 , with a mean score of 0.82 . $^{(27)}$ Reliability and validity of the Farsi version of the HADS were confirmed. ${ }^{(28)}$ This scale has been used for patients with heart diseases in a previous study. ${ }^{(29)}$ A cutoff score greater than 8 for the diagnosis of either anxiety or depression has been suggested. ${ }^{(30)}$ The quantitative score of both subscales ranged from 0 to 21 under the categorization of normal (0-7), borderline (8-10), and abnormal (11-21). A higher score indicated a higher level of anxiety or depression. Scores 11 or higher on the anxiety or depression subscales indicated the probability of either anxiety or depression disorder. ${ }^{(26)}$

\section{Intervention}

The foot reflexology massage intervention was performed by the first researcher (TB) as a qualified therapist, who successfully passed required training courses on reflexology massage.

In the morning work shifts, beside the routine care in the $\mathrm{CCU}$, the researcher implemented foot 
reflexology massage for each participant in the intervention group, after which their baseline hospital anxiety and depression were measured. The participants were placed on a bed in the supine position and a pillow was placed under their knees. The researcher sat at the bottom of the bed and rubbed the palmar surfaces of her hands against each other to make them warm. Next, the dorsal and the plantar surfaces of one foot were lubricated using sweet almond oil and were massaged. After general foot massage, relaxing techniques were performed including effleurage movements (10 times), stretching fingers by holding them between thumbs and other fingers ( 5 times in both directions), and moderate rotational movements around the ankle (5 times). Next, the reflex zones of solar plexus, pituitary gland, brain, heart, large and small intestines, vertebral column, adrenal, and kidney were used for the stimulation. The researcher exerted firm downward pressure with her thumbs in the above-mentioned areas for 14 secs in the heart area, 5 times for each intestine, and 5 times for the adrenal gland and kidney. The rubbing technique was used for adrenal and kidney reflex zones. In total, reflexology massage of both feet lasted for a total of $20 \mathrm{~min}$ (10 min for each foot). The participants were asked to complete the HADS before and after the intervention.

After the assessment of hospital anxiety and depression in the control group, at the same time as the reflexology group (i.e., in the morning shift and in the same environment), the control group only received routine care without foot reflexology massage. Routine care included hemodynamic measurements, drug therapy, physicians' visit, and nursing care performed for patients admitted to the CCU. It should be noted that nursing duties and staffing patterns remained unchanged throughout the study process. Also, nursing staff and the participants' family members were requested not to enter the intervention room, so as to minimize disruptions and enhance the participants' relaxation. No harm or side effects were reported throughout the trial.

\section{Randomization}

Following receipt of the ethical committee's approval and the permission to enter the research zone, the head nurse of the CCU was informed of the study's aim and process. She helped with identification of eligible participants based on the inclusion criteria. Allocation of the participants to the groups happened during the week that the researchers visited the hospital. A system of sealed envelopes was used for the random assignment of the eligible participants into the groups, with each envelope assigned to a specific group. The sampling process continued until a sufficient number of the participants were assigned to each group. The second author (NR) generated the random allocation sequence, while the first author
(TB) enrolled the subjects and assigned them to the intervention and control groups. It was impossible to blind the participants or nursing staff to the group assignment due to nature of the intervention. However, the data analyst (SDT) was unaware of the group assignment. In addition, the randomization codes were available only to a research fellow who was not connected to this study, and were disclosed after data analysis.

\section{Data Analysis}

Data analysis was performed using descriptive (frequency, percentage, mean, and standard deviation) and inferential (independent $t$ test, Chi-square test, Fisher's exact test, $2 \times 2$ repeated measure ANOVA, Eta correlation ratio) statistics via the SPSS version 21.0 software (SPSS Inc., Chicago, IL). The Kolmogorov-Smirnov test was used to assess data in terms of normal distribution. $P<.05$ was considered statistically significant.

\section{Ethics Statement}

The first author explained the study's aim and process to the eligible participants and ensured them about confidentiality of data and safety of the intervention. Each participant signed a written informed consent form. The institutional review board approval was granted by the University in which the second author worked. The ethical considerations of this study conformed to the Declaration of Helsinki 1995, revised 2001. Numbers, rather than names, were used to de-identify the participants to ensure their confidentiality and anonymity. However, a cardiologist was available in the CCU to intervene, if required. No patient withdrew from the study and no adverse effects were identified as occurring throughout the study.

\section{RESULTS}

\section{Demographic Characteristics of the Participants}

No statistically significant differences between the groups in terms of demographic characteristics including age, the marital status, education level, employment status, living status, and history of hospitalization were reported $(p>.05)$. Therefore, the groups were homogenous in terms of the abovementioned characteristics (Table 1).

\section{Hospital Anxiety and Depression}

The mean and standard deviation of the anxiety measure of the HADS assessment changed from 13.77 \pm 4.39 (before the intervention) to $8.53 \pm 3.70$ (after the intervention) in the intervention group, and from 
TABle 1. Demographic Characteristics of the Participants $(n=45$ in each group)

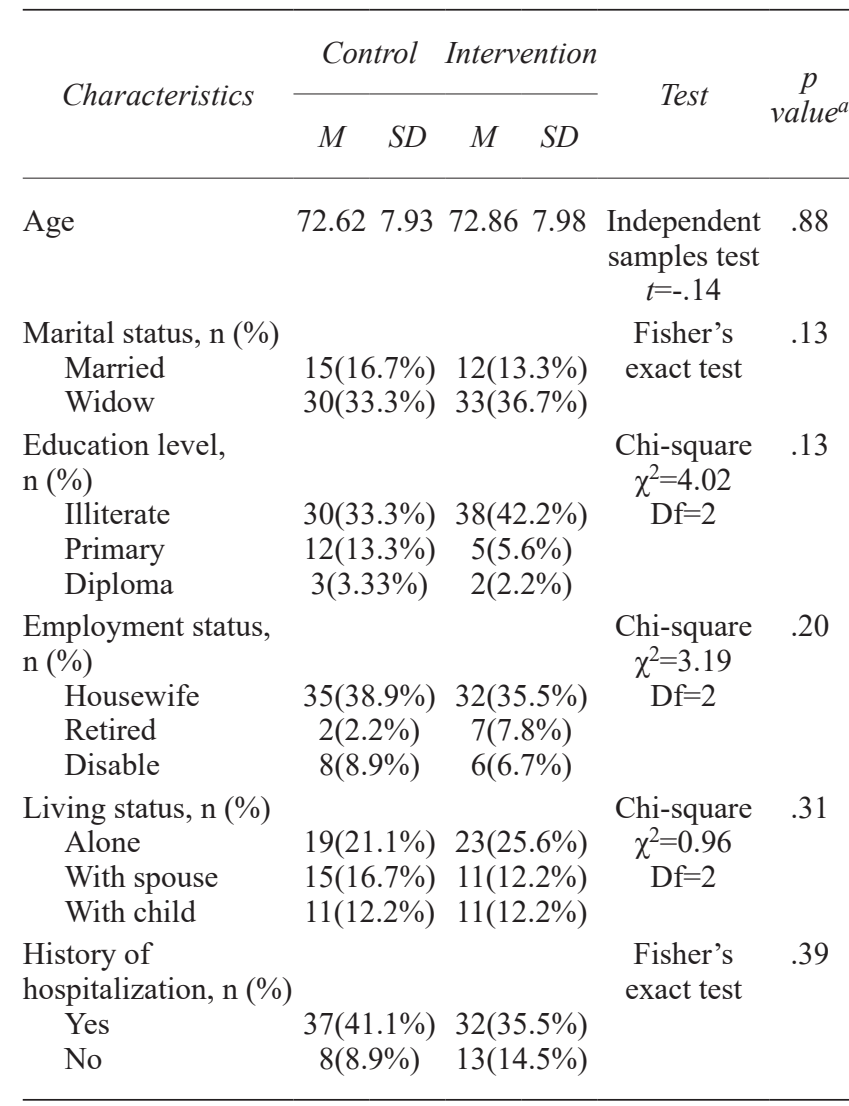

${ }^{\text {a }} P$ value was calculated using the independent $t$ test, Chi-square test, and Fisher's exact test for group comparisons. The data were normal according to the Kolmogorov-Smirnov test $(p>.5)$. $\mathrm{M}=$ mean; $\mathrm{SD}=$ standard deviation.

$11.66 \pm 4.24$ to $11.06 \pm 3.19$ in the control group. The analysis of two-way repeated measures ANOVA revealed an interaction for the outcome measure anxiety indicting that foot reflexology massage significantly decreased anxiety relative to the control intervention $(\mathrm{F}(1.44)=19.11, p=.001)$. Also the eta ratio showed a correlation between foot reflexology massage and anxiety $\left(\operatorname{xxet}^{2} p=.39\right)$ and the intervention had a large effect on the anxiety level (Table 2). The main effect of treatment group assignment was not significant for anxiety $(\mathrm{F}(1.44)=0.10, p=.74)$, but there was a main effect for time $(\mathrm{F}(1.44)=28.08, p=.001)$

The mean and standard deviation of the depression measure of the HADS assessment changed from 13.66 \pm 4.64 (before the intervention) to $8.44 \pm 3.66$ (after the intervention) in the intervention group, and from $11.93 \pm 4.30$ to $11.11 \pm 3.42$ in the control group. Regarding the level of depression, the two-way RMANOVA detected a statistically significant interaction between the groups indicating that foot reflexology massage reduced depression $(\mathrm{F}(1.44)=16.76, p=$ $.001)$. Moreover, the eta ratio showed a correlation between the intervention and depression $\left(\mathrm{xxet}^{2} p=.27\right)$
TABle 2. Comparison of Mean Scores of Hospital Anxiety and Depression Before and After the Intervention

\begin{tabular}{lccc}
\hline & $\begin{array}{c}\text { Before } \\
\text { Intervention }\end{array}$ & $\begin{array}{c}\text { After } \\
\text { Intervention }\end{array}$ & $\begin{array}{c}\text { Statistical } \\
\text { Analysis of the } \\
\text { Intervention }\end{array}$ \\
\hline $\begin{array}{l}\text { Hospital. Anxiety } \\
\text { Control }\end{array}$ & $11.66 \pm 4.24$ & $11.06 \pm 3.19$ & $\mathrm{~F}(1.44)=19.11$, \\
$\begin{array}{l}\text { Intervention } \\
\text { Hospital. Depression }\end{array}$ & $11.74 \pm 4.29$ & $11.11 \pm 3.42$ & \\
$\begin{array}{l}\text { Control } \\
\text { Intervention }\end{array}$ & $13.66 \pm 4.64$ & $8.42 \pm 3.62$ & $\begin{array}{c}\mathrm{F}(1.44)=16.76, \\
p=.001\end{array}$ \\
\hline
\end{tabular}

Data are presented as means $\pm \mathrm{SD}$.

signifying that foot reflexology massage had a large effect on the depression level (Table 2). The main effect of group was not significant for depression $(\mathrm{F}(1.44)=0.28, p=.59)$, but there was a main effect of time $(\mathrm{F}(1.44)=16.76, p=.001)$.

\section{DISCUSSION}

In this study, foot reflexology massage reduced anxiety and depression in the older women with ACS. The levels of hospital anxiety and depression in the intervention group significantly decreased compared to that of the control group.

As a non-pharmacological intervention, foot reflexology massage is an effective therapy. For instance, according to Soheili et al., ${ }^{(20)}$ reflexology helped with alleviating anxiety and depression in women with multiple sclerosis. The results of the present study were in line with the findings of the study by Moghimi Hanjani et al. (31) indicating the effect of foot reflexology massage on the reduction of anxiety and depression in primigravida women. Similarly, Shahsavari et al. ${ }^{(32)}$ also investigated the effect of foot reflexology massage on anxiety and physiological parameters among bronchoscopy candidates using the massage on pituitary, solar plexus, heart, and lung reflex points. They found that foot reflexology alleviated patients' anxiety and improved their physiological parameters. Also, the study by Mortazavi et al. ${ }^{(33)}$ showed higher symptom improvements after massage in subjects during labor. Conversely, Hudson et al. ${ }^{(34)}$ reported that reflexology did not significantly increase the study outcomes in patients undergoing minimally invasive surgeries and local anesthesia. A probable reason for variations in the results of studies could be methodological differences, including sampling and the intervention process.

It is believed that reflexology helps body systems return to the natural state and reduce symptoms of a disease. ${ }^{(35)}$ Also, reflexology can affect psychological indicators more than biometric parameters. ${ }^{(36)}$ Physiological changes, such as the increased blood 
circulation and muscle relaxation, are the main consequences of reflexology massage that improve patient's comfort. ${ }^{(37)}$

Inconsistencies in maps and points used for reflexology massage are considered major interventional problems for patients with cardiac diseases, ${ }^{(38)}$ which may explain reasons for differences in the results of the Gunnarsdottir and Jonsdottir's study ${ }^{(21)}$ with those of the present study. Williamson et al. ${ }^{(39)}$ showed that foot reflexology massage was not more effective than non-specific foot massage for relieving psychological symptoms during menopause. Differences in techniques used for reflexology, and number and length of reflexology sessions, could account for differences in the results.

\section{Study Limitation}

The examination of baseline anxiety between the groups indicated some differences, which could be caused by the small sample size in this study. However, the groups were homogenous in other characteristics. Also, the long-term assessment and follow-up of anxiety and depression in the older women after reflexology massage were not conducted due to a lack of feasibility.

\section{Recommendation for Further Research}

Future studies with a larger sample size and longterm follow-up are needed to examine the effect of foot reflexology massage on psychological parameters in cardiac patients. Moreover, the usefulness of alternative and complementary techniques in older adults needs further studies.

\section{CONCLUSION}

Foot reflexology massage is an efficient and safe intervention for alleviating psychological responses among female older adults suffering from ACS. Therefore, this safe and non-pharmacological intervention can be used, along with pharmacological measures, to reduce psychological symptoms and improve quality of care in patients with ACS.

\section{ACKNOWLEDGMENTS}

This research was supported financially by a grant from Shahed University, Tehran, Iran (decree code: $\mathrm{P} / \mathrm{A} / 13 / 93$ ). Ethical approval was given by the ethics committee of Shahed University (No. 41-228111).

\section{CONFLICT OF INTEREST NOTIFICATION}

The authors declare there are no conflicts of interest.

\section{COPYRIGHT}

Published under the CreativeCommons AttributionNonCommercial-NoDerivs 3.0 License.

\section{REFERENCES}

1. Chamberlain AM, Vickers KS, Colligan RC, Weston SA, Rummans TA, Roger VL. Associations of preexisting depression and anxiety with hospitalization in patients with cardiovascular disease. Mayo Clin Proc. 2011;86(11):1056-1062.

2. Meneghetti CC, Guidolin BL, Zimmermann PR, Sfoggia A. Screening for symptoms of anxiety and depression in patients admitted to a university hospital with acute coronary syndrome. Trends Psychiatry Psychother. 2017;39(1):12-18.

3. Tajfard M, Mobarhan MG, Rahimi HR, Mouhebati M, Esmaeily H, Ferns GA, et al. Anxiety, depression, coronary artery disease and diabetes mellitus; an association study in Ghaem Hospital, Iran. Iran Red Crescent Med J. 2014;16(9):e14589.

4. Pelletier R, Bacon SL, Arsenault A, Dupuis J, Laurin C, Blais $\mathrm{L}$, et al. Relative associations between depression and anxiety on adverse cardiovascular events: does a history of coronary artery disease matter? A prospective observational study. BMJ Open. 2015;5(12):e006582.

5. Knight BG, Durbin K. Aging and the effects of emotion on cognition: Implications for psychological interventions for depression and anxiety. PsyCh J. 2015;4(1):11-19.

6. Saraçlı Ö, Akca ASD, Atasoy N, Önder Ö, Şenormancı Ö, Kaygisız İ, et al. The relationship between quality of life and cognitive functions, anxiety and depression among hospitalized elderly patients. Clin Psychopharmacol Neurosci. 2015;13(2):194-200.

7. Zisberg A. Anxiety and depression in older patients: the role of culture and acculturation. Int J Equity Health. 2017;16(1):177.

8. Boyd CM, Xue QL, Guralnik JM, Fried LP. Hospitalization and development of dependence in activities of daily living in a cohort of disabled older women: the Women's Health and Aging Study I. J Gerontol A Biol Sci Med Sci. 2005;60(7):888-893.

9. Ferrell-Torry AT, Glick OJ. The use of therapeutic massage as a nursing intervention to modify anxiety and the perception of cancer pain. Cancer Nurs. 1993;16(2):93-101.

10. Kunz K, Kunz B. The Complete Guide to Foot Reflexology (revised). Albuquerque, NM: Reflexology Research Project; 1993.

11. Pitman V, MacKenzie K. Reflexology: a practical approach. Cheltenham, UK: Nelson Thornes; 2002.

12. Field T. Massage therapy research review. Complement Ther Clin Pract. 2014;20(4):224-229.

13. Jones J, Thomson P, Lauder W, Howie K, Leslie SJ. Reflexology has no immediate haemodynamic effect in patients with chronic heart failure: a double blind randomised controlled trial. Complement Ther Clin Pract. 2013;19(3):133-138.

14. Tiran D, Chummun $H$. The physiological basis of reflexology and its use as a potential diagnostic tool. Complement Ther Clin Pract. 2005;11(1):58-64.

15. Poole H, Glenn S, Murphy P. A randomised controlled study of reflexology for the management of chronic low back pain. Eur J Pain. 2007;11(8):878-887. 
16. Ferrer de Dios R. [Reflexology] (article in Spanish). Rev Enferm. 2005;28(3):42-46.

17. Abbaszadeh Y, Allahbakhshian A, Seyyedrasooli A, Sarbakhsh P, Goljarian S, Safaei N. Effects of foot reflexology on anxiety and physiological parameters in patients undergoing coronary artery bypass graft surgery: a clinical trial. Complement Ther Clin Pract. 2018;31:220-228.

18. Dikmen HA, Terzioglu F. Effects of reflexology and progressive muscle relaxation on pain, fatigue, and quality of life during chemotherapy in gynecologic cancer patients. Pain Manag Nurs. 2019;20(1):47-53.

19. McCullough JE, Liddle SD, Close C, Sinclair M, Hughes CM. Reflexology: a randomised controlled trial investigating the effects on beta-endorphin, cortisol and pregnancy related stress. Complement Ther Clin Pract. 2018;31:76-84.

20. Soheili M, Nazari F, Shaygannejad V, Valiani M. A comparison the effects of reflexology and relaxation on the psychological symptoms in women with multiple sclerosis. J Educ Health Promot. 2017;6:11.

21. Gunnarsdottir TJ, Jonsdottir H. Does the experimental design capture the effects of complementary therapy? A study using reflexology for patients undergoing coronary artery bypass graft surgery. J Clin Nurs. 2007;16(4):777-785.

22. Sibbritt D, Davidson P, DiGiacomo M, Newton P, Adams J. Use of complementary and alternative medicine in women with heart disease, hypertension and diabetes (from the Australian Longitudinal Study on Women's Health). Am J Cardiol. 2015;115(12):1691-1695.

23. Mahmoudirad G, Ghaedi Mosolo M, Bahrami H. Effect of foot reflexology on anxiety of patients undergoing coronary angiography. Iranian J Crit Care Nurs. 2014;6(4):235-242.

24. Faraji J, Fallahi Khoshknab M, Khankeh H. The effect of poetry therapy on the cognitive status in elderly residents of a nursing home. Complement Med J Fac Nurs Midwifery. 2013;2(4):312-323.

25. Bakhtiyari F, Foroughan M, Fakhrzadeh H, Nazari N, Najafi B, Alizadeh M, et al. Validation of the persian version of Abbreviated Mental Test (AMT) in elderly residents of Kahrizak charity foundation. Iranian J Diabetes Metabol. 2014;13(6):487-494.

26. Zigmond A, Snaith R. The hospital anxiety and depression scale. Acta Psychiatr Scand. 1983;67(6):361-370.

27. Bjelland I, Dahl AA, Haug TT, Neckelmann D. The validity of the Hospital Anxiety and Depression Scale: an updated literature review. J Psychosom Res. 2002;52(2):69-77.

28. Montazeri A, Harirchi I, Vahdani M, Khaleghi F, Jarvandi S, Ebrahimi M, et al. The European Organization for Research and Treatment of Cancer Quality of Life Questionnaire (EORTC QLQ-C30): translation and validation study of the Iranian version. Support Care Cancer. 1999;7(6):400-406.
29. Barth J, Martin CR. Factor structure of the Hospital Anxiety and Depression Scale (HADS) in German coronary heart disease patients. Health Qual Life Outcomes. 2005;3(1):1-9.

30. Stafford L, Berk M, Jackson HJ. Validity of the Hospital Anxiety and Depression Scale and Patient Health Questionnaire-9 to screen for depression in patients with coronary artery disease. Gen Hosp Psychiatry. 2007;29(5):417-424.

31. Moghimi-Hanjani, S., Z. Mehdizadeh-Tourzani, and M. Shoghi, The Effect of Foot Reflexology on Anxiety, Pain, and Outcomes of the Labor in Primigravida Women. Acta Med Iran, 2015. 53(8): p. 507-11.

32. Shahsavari H, Abad ME, Yekaninejad MS. The effects of foot reflexology on anxiety and physiological parameters among candidates for bronchoscopy: a randomized controlled trial. Eur J Integrative Med. 2017;12:177-181.

33. Mortazavi H, Khaki S, Moradi R, Heidari K, Rahimparvar SFV. Effects of massage therapy and presence of attendant on pain, anxiety and satisfaction during labor. Arch Gynecol Obstet. 2012;286(1):19-23.

34. Hudson BF, Davidson J, Whiteley MS. The impact of hand reflexology on pain, anxiety and satisfaction during minimally invasive surgery under local anaesthetic: a randomised controlled trial. Int J Nurs Stud. 2015;52(12):1789-1797.

35. Embong NH, Soh YC, Ming LC, Wong TW. Perspectives on reflexology: a qualitative approach. J Tradit Complement Med. 2017;7(3):327-331.

36. McVicar A, Greenwood C, Ellis C, LeForis C. Influence of study design on outcomes following reflexology massage: an integrative and critical review of interventional studies. $J$ Alt Complement Med. 2016;22(9):739-750.

37. Morey JH. Integrative reflexology: a therapy within a naturopathic nursing practice. Explore (NY). 2005;1(5):400-401.

38. Jones J, Thomson P, Lauder W, Leslie SJ. Reported treatment strategies for reflexology in cardiac patients and inconsistencies in the location of the heart reflex point: an online survey. Complement Ther Clin Pract. 2012;18(3):145-150.

39. Williamson J, White A, Hart A, Ernst E. Randomised controlled trial of reflexology for menopausal symptoms. BJOG Int $J$ Obstetr Gynaeocol. 2002;109(9):1050-1055.

Corresponding author: Nahid Rejeh, Department of Nursing, Faculty of Nursing and Midwifery, Shahed University, Opposite of Holy Shrine of Imam Khomeini-Khalij Fars Expressway, Postal/zip code: 3319118651, Tehran, Iran

E-mail: reje@shahed.ac.ir 